\title{
Understanding the Role of User Interface Design in Fostering Students' Learning Process in A Multimedia Courseware Learning Environment: Insights from a Malaysian Case Study
}

\author{
Kishabale Bashir*
}

\begin{abstract}
The increased availability and use of information and communication tools such as multimedia courseware design in education, has gained the attention of instructors and multimedia developers in a bid to foster student learning. However, there is still scanty literature with regard to how user interface design of multimedia course environments fosters student learning process. The purpose of this study was to explore the students of a higher learning institution in Malaysia's perceptions on how user interface design fosters their learning process in a multimedia courseware. This study adopted a qualitative design with semi-structured interviews as the data collection tool. Two postgraduate students participated in the in-depth interviews after learning from a multimedia module on how to use the Excel software. Thematic analysis was used to derive meaning from students' experiences with the learning courseware. From the interviews, it was found that the nature and usability of the interface design of multimedia courseware influences learning motivation, interactivity and cognitive load. The participants also identified software and hardware issues as the key challenges in using the multimedia courseware. Suggestions on how to improve future multimedia courseware were also noted. It is also recommended that further studies be carried on larger samples, using other research approaches and designs to allow for generalisability of the research findings.
\end{abstract}

Keywords: User interface design, Learning process, Multimedia learning environment, Learning motivation, Cognitive load, Interactivity

\section{Introduction}

Student learning in the era of information technologies is increasingly being supported by a wide array of technological affordances, the most peculiar among these being multimedia courseware with various user interface designs. The user interface is a collection of methods, tools and procedures that act as a point of interaction between user and computer software with elements like text, graphics and interactive tools that enable the explanation of concepts and instructions (Faghih, Reza and Katebi, 2013; Galitz, 2007; Centers for Disease Control and Prevention, 2013). User interfaces are important in creating appropriate schemas in the users' brain for effective information acquisition (Khan, 2012). Thus learning effectiveness is closely related with the design of an E-learning interface as the latter has an effect on learning motivation, interactivity and cognitive load. The goal of

\footnotetext{
* Kulliyyah of Education, International Islamic University Malaysia
} 
student learning in any e-learning environments may not be achieved if there is a mismatch between the user interface design and user characteristics however much learning content is well organised and learners motivated to learn. To that end, the ease of use of an Elearning software, the nature of content and learner interactions with it are presented and enabled by the user interface (Faghih, Reza and Katebi, 2013; Woo (2009).

Well-designed interfaces for Multimedia learning courseware with clear instructions do not require the learner to figure out what to do on each page again and again or make the learner feel ignorant or technically hopeless. That is why Dorian (2014) has cautioned that poor interface design can get in the way of learning by slowing it down, imposing hurdles, and using up precious cognitive load. The implication therefore is that user interface designers for learning courseware have to take into consideration the limitations of the working memory during the design of user interfaces as excessive cognitive load for learning would have a negative impact (Rau, 2014).

One of the goals of interactive educational courseware is to motivate and help learners to learn meaningfully and assist them to be engaged more in their learning. Yet the nature interface design of such educational software affects how the learners understand the content and their desire to use it. Thus the user interface design should be integrated and reflected in the courseware development process so that the cognitive and emotional effort of the students is directed towards the learning task (Kamaruddin, Park and Hyun, 2009). To that end, meaningful student learning can only be realised with the appropriate presentation of the interactive materials that enable learners to learn in a more effective way and for improved learning outcomes.

\section{Theoretical Framework}

This study integrated the ARCS motivation theory (Keller, 1988), Cognitive load theory (Sweller, 1988) and three-way model for computer-initiated interaction Evans and Sabry (2003) to form a theoretical basis for understanding students' perceptions on how user interface design fosters their learning process in multimedia courseware. Figure 1 illustrates the conceptual derived from the theoretical review.

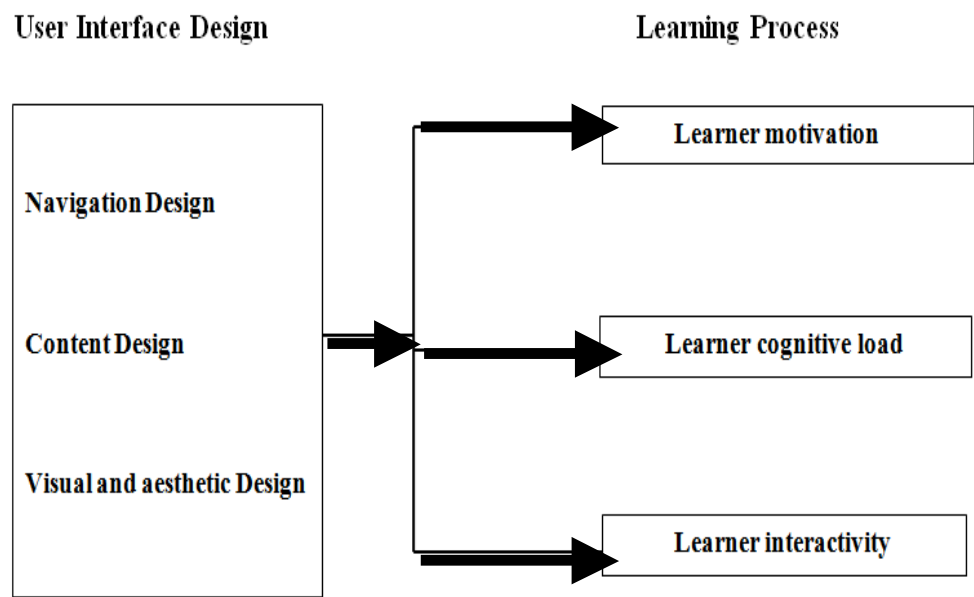

Figure 1: Conceptual frame work or model relating user interface design and learning process in multimedia courseware. 
According ARCS Model of Motivation (Keller, 1988), there are four key elements in the learning process which can encourage and sustain learners' motivation. These four elements form the acronym ARCS of the model and stand for Attention, Relevance, Confidence and Satisfaction (ARCS). The ARCS model has its roots in the Tolman and Lewin's expectancy-value theory, which postulates that individuals are motivated to learn if they see value in the knowledge present to them and if there are opportunities for success. Meanwhile, Sweller (1988)'s Cognitive Load Theory suggests that learning happens best under conditions that are aligned with human cognitive architecture. Cognitive Load Theory also shows us that working memory can be extended in two ways. First, the mind processes visual and auditory information separately. Auditory items in working memory do not compete with visual items in the same way that two visual items, for example a picture and some text, compete with one another. Second, working memory treats an established schema as a single item, and a highly practiced "automated" schema barely counts at all. So, learning activities that draw upon your existing knowledge expand the capacity of your working memory. Lastly, the three-way model for computer-initiated interaction (3WMI) as proposed by Evans and Sabry (2003) involves a sequence of three actions; initiation, response and feedback, with each action involving a one-way flow of information between two agents.

Despite its significance, the area of user interface design and its influence on student learning process in multimedia courseware is still an under studied area. Moreover, many of the existing studies are not focusing directly on interface design and learning process in multimedia courseware which is the aim of this study. For example Bakri (2014) looked at a conceptual framework for Arabic Language courseware using Persuasive Design; while Wan Isa et al. (2010) studied the development and innovation of multimedia courseware for teaching and learning of KAFA subjects. Mukundan and Nimehchisalem (2011) did a study on English Language Teaching Courseware in Malaysia. Ibrahim, Yusuf, Zohdi, Amin and Basir (2016) assessed interactive courseware for Quranic verses on the integration of Naqli and Aqli Knowledge. Ahmad, Ahmad and Wan (2015) studied the extent to which Multimedia Design Principles in developing Virtual Reality Learning Application increases students' knowledge in Islamic funeral rites. None of these empirical studies have directly addressed the how question regarding interface design and learning process in multimedia courseware.

This study is urgent and timely because as student learning effectiveness and interface design are substantially intertwined, a clear understanding of how student learning is fostered becomes crucial. Hence the need for this study to clearly understand how the design of user interfaces affects student learning process in multimedia courseware to fill up such existing literature gaps.

The purpose of this study was to explore students' perceptions on how the user interface design of a multimedia courseware fostered student learning process in Faculty of Education at a Higher Education institution in the state of Selangor, Malaysia. The findings will go a long way to provide insights regarding future design of multimedia learning courseware. 


\section{Research Questions}

This study sought to answer the following research questions:

1. How does user interface design foster student learning motivation in multimedia courseware?

2. How does user interface design help to manage cognitive load in multimedia courseware?

3. How does user interface design foster student learning interactivity in multimediaenhanced courseware?

4. What user interface design challenges did learners face while using the multimedia courseware?

5. What are students' recommendations for the improvement of the user interface design of multimedia courseware for better learning process and outcomes?

\section{User Interface Design and Learning Motivation}

Learning motivation is defined as an internal drive that propels learner behavior and gives it direction to the attainment of a learning goal. User interface design for learning courseware seeks to promote rich, engaging interactions between learners and software, and in order for this experience to unfold, the user must be motivated to initiate an interaction with the technology (O'Brien, 2010). Therefore, an ideal interface for learning is easy to use and aesthetically pleasing because the interface design of learning system affects learner's learning, motivation, satisfaction, learning efficiency, and quality of interaction (Chun-Yi, and Hao-Ping, 2014).

Several empirical studies attest to the effect of user interfaces on student learning motivation. For example Stefan and Moldoveanu (2015) have reported high levels of student motivation in a gamified 3D virtual learning environment; Yet Omaleb (2010) in an exploratory study on the use of 3-D multi-user virtual environments for online problembased learning found that that the avatar attribute personalized interaction and sustained learner engagement and motivation. In a related study, Estapa and Nadolny (2015) report that students were clearly motivated in the Augmented Reality, hence supporting prior studies that indicated the use of Augmented Reality in classroom contexts can foster learner motivation. Additionally, Wang and Reeves (2007) in their study on the effect of a web-based learning environment on student motivation in a science course, found that half of the students interviewed stated that, because they were visual learners, their interest in learning with web-based learning environment was greater than their interest in learning in a traditional classroom. Video, animation and sound effects were major components that made students feel excited.

In a study on the effectiveness of Robot-Assisted Language Learning (RALL), using a pretest/post-test design, Lee, Noh, Lee Kyusong, Garrry, Lee and Seongdae (2011) report that RALL promoted and improved students' satisfaction, interest, confidence, and motivation. Closely related to the above results, Hong, Huang, Hsu and Shen (2016) did a study on Authoring Robot-Assisted instructional materials for improving learning performance and motivation. The post-test results revealed that the experimental group outperformed the control group, particularly in terms of the improvement of listening, reading skills and learning motivation. 


\section{User Interface Design and Learning Cognitive Load}

Learning cognitive load can be conceptualised as the totality of mental effort the learner uses in the working memory to accomplish a learning goal. The user interface's visual design, in terms of text style, background color and the degree of visual complexity in the multimedia courseware can either enhance or degrade screen readability. As a consequence, it may increase extraneous cognitive load and interference with learning retention. For example color coding can degrade cognitive processing since the learner tends to associate specific concepts with a particular color. Moreover, color repetition for a different concept equally increases extraneous cognitive load (de koning, Tabbers, Rikers and Paas, 2009). Careful selection of text and background colors of multimedia learning environments can enhance the readability of on-screen text and hence minimizing extraneous cognitive load and boosting student learning. Better still, luminance contrast between background and text can have a powerful effect on readability (Richardson, Drexler, and Delparte, 2014).

Several past literatures support the relationship between user interfaces and learner cognitive load. For example Hsiung and Lai (2013) in an experimental study on improving learning and reducing cognitive load through $3 \mathrm{D}$ courseware found that students receiving lecture and instructions enabled by 3D courseware outperformed the other three methods in learning results. The above findings are further strengthened by Sii and Soon (2010) who found that additional redundant information that are relevant to the contents within and across the visual and aural channels provide greater reinforcement in organizing and structuring information issuing in better learning. Additionally, in a study on integrating Annotations into a Dual-slide PowerPoint Presentation for classroom learning, Lai, Tsai and $\mathrm{Yu}$ (2011) found that the proposed system based on cognitive theory can effectively enhance learning with dual-slide PowerPoint presentation than that of the conventional group.

$\mathrm{Li}$ and Chen (2010) in their experimental study to compare Topic Browser interface with conventional tabbed browser interface indicated that Topic Browsers lowered the level of disorientation, increased learners' retention, and fostered their efficiency in completing tasks. The implication is that well-organized information can significantly reduce disorientation and cognitive load and thus can improve student learning in multimedia courseware. Although in contrast, studies by Schrader and Bastiaens (2012) and Micheal (2009) found no differences in learner cognitive load ratings.

Hsu, Chang and Yu (2012) did a study on learning effectiveness and cognitive loads in instructional materials of programming language on single and dual screens using quasi-experimental design with forty-two undergraduates. The results showed significant differences in learning effectiveness, and the degrees of clarity and difficulty of instructional materials in both learning environments. This study may help instructors with a better understanding of how a dual-screen learning environment affects learning effectiveness and cognitive loads in programming language instruction. In a study on reducing cognitive load and enhancing usability through a reduced graphical user interface for a dynamic geometry system by Reis et al. (2012), the experimental results indicate that an interface that hides advanced and extraneous features helps novice users to perform slightly better than novice users using a complete interface. In another study on effects of color and animation on visual short-term memory in Computer-Environment Learning 
Tasks using repeated-measures Factorial Analysis of Variance design, Debiase (2009) found that achromatic color information interferes with visual short-term memory learning tasks in specific contexts.

Glen (2010) carried out a study using a quasi-experimental design to examine whether interactive visuals produce increased mathematics learning compared to the use of static images. The findings indicated that the use of interactive visuals was not associated with lower cognitive load than the use of static images. It has also been found that the type of user interface for a multimedia courseware significantly impacts on student learning process. For example Chandrasekera and Yoon (2015) in a study on the effect of tangible user interfaces on Cognitive Load found out that that epistemic action in tangible user interfaces such as Augmented Reality interfaces reduces cognitive load. In support of the above finding, (Cheon and Grant, 2016) in a study on the effects of metaphorical interface on germane cognitive load in Web-based instruction found that a metaphorical interface enhanced learners' germane cognitive load and learning performance.

Lastly, Currie (2008) suggests that using visuals in multimedia helps learners to actively reconstruct significant schematics to compensate for extraneous load caused as a result of the animation quality. The suggestion offered by Curie (2008) is exemplified in (Wang, Chen and Wu (2015)'s study that found the effects of different video lecture types on sustained attention, emotion, cognitive load, and learning performance. Their findings show that cognitive load related to the voice-over type was significantly higher than that of lecture capture and picture-in-picture types. Furthermore, the cognitive load for visualizers markedly exceeds that of verbalizers who are presented with the voice-over type.

\section{User Interface Design and Learning Interactivity}

In computer use, interactivity is the dialog that occurs between a human being (and possibly another live creature) and a computer program. Learning interactivity signifies the active learner participation in the instructional process and gives the learner some control over the pace and sequence of the instruction. Perhaps one of the potential benefits of using web-based learning systems lies in their provision for interactivity, as they can provide intrinsic feedback on the actions of the learner. Learning interaction can be categorised into student initiated interaction and computer initiated interaction. In the former, the student seeks some information from the content similar to looking up in a book or watching a television programme. In the latter, the system requires some input from the learner like pressing a button or answering a question (Evans and Sabry, 2003).

Recent studies have attempted to evaluate the level of interactivity and the ability to learn and understand in online multimedia environments. Neo, Neo, and Tan, (2012) in their study on applying authentic learning strategies in a multimedia and web learning environment in the Malaysian students' perspective found that students reported positively towards learning in this environment and to the authentic activities in the modules, which allowed them to do well in their project. Yet in a study on effectiveness of electronic textbooks with embedded activities on student learning using experimental design by Thornton, Ph, and Mentor (2010), survey results indicated that students preferred using an electronic textbook versus a hardcopy textbook and motivated to participate in classroom group problem-based activities versus independent problem-based activities provided in the electronic textbook. 
In a study on interactivity and flow in a blended course, Yerasimou (2010) found from the study that interactivity and flow elements are critical to consider when designing blended learning to advance learners' motivation and active participation. Similarly, in a study on using multimedia interactive programs and learning basic maths skills, Al-kabi and Sharadgah (2015) found that using multimedia enhanced methods of teaching can be effective in getting students attention especially when cartoon characters are used.

Tsang (2010) in a study on learner-content interactions and learning effectiveness using qualitative method revealed that a combination of various types of content presentation was the most effective catalyst to their learning, compared with single-media presentations and text-based online content ranked lowest in terms of motivation and engagement in learning. In another study on the role of interactivity in student satisfaction and persistence in online learning, Croxton (2014) found that interactivity is an important component of satisfaction and persistence for online learners, and that preferences for types of online interactivity vary according to type of learner.

\section{Methodology}

This study was designed qualitatively based on in-depth interviews. The major idea behind employing the qualitative paradigm was to gain a deeper understanding of what it means to use a multimedia learning courseware and the process of learning. Besides the informants were able to freely express their opinions in detail unlike if it was in a survey study. Thus this phenomenological study aimed at determining the experiences learners had with multimedia courseware interface for their learning and were able to provide a comprehensive explanation or description of it.

\section{Participants}

The researcher purposively selected two informants for the study. This decision was based on the argument by Baker and Edwards (2012) that whereas qualitative researchers study fewer informants, they delve more deeply into those informants, with the hope of generating their subjective understanding and perception of phenomena. The implication therefore is that the question of "how many" does not hold much water in qualitative research. Two male doctoral students, one specializing in Educational Psychology in his final semester of study and the other in Educational Leadership were selected for the interview sessions. The informants were from an Islamic University in Selangor, Malaysia. The two informants' selection was based on their level of English proficiency and good command of ICT skills to use computer technology for learning.

\section{Data Collection Procedure and Instrumentation}

Prior to the interviews, the informants were given an E-learning module on ICT skills and they were asked to choose and learn the topic on Spreadsheet software. In addition, the informants were given a printed manual of how to load and manage the E-learning module on their computers to reduce on the learning obstacles. Each informant was given 24 hours to learn about the topic on Spreadsheet software and was then interviewed the following day at their convenience. Before the interview, consent forms were issued to each of the informants and they signed the form on a voluntarily.

All interviews were guided by the same protocol of interview for purposes of consistency in results. The interview questions prompted the informants to share their 
experiences regarding the multimedia courseware and their learning process. The audio recorder was used to record the informants' responses upon their permission, with the duration of the interview sessions lasting 30 to 35 minutes using in English language.

\section{Data Credibility and Trustworthiness}

To ensure credibility and worthiness of the results, this study paid attention to piloting and evaluation of generated themes. First, a pilot interview was conducted prior to the actual interview so as to improve the quality of the interview questions. The pilot study was also to help investigate if the interview questions to be used probe well in order to answer research questions and if the multimedia courseware to be used had a fair usability standard. From the pilot interview, the researcher concluded that the interviewee was clear with most of the interview questions and could answer most of the questions. Minor changes were made to merge some of the interview questions.

Secondly, to ensure the credibility and trustworthiness of the data, the generated themes were forwarded to two inter-raters who were experts in the area of multimedia for learning to evaluate the generated themes. The aim was to validate that the researcher has developed the themes correctly. The average of inter-raters' agreements was $95 \%$ which indicated that the researcher's interpretation was representative and appropriate.

\section{Data Analysis}

Thematic data analysis technique was employed in the process. In that case, data analysis started with transcribing the audio-recorded interviews verbatim with the help of Express Scribe Transcription Software. In order to ensure the accuracy of the transcripts, a transcription data matrix was created for each interview which clearly indicated discourse units from both the research and the informant.

Secondly, a 7-column matrix was created to help generate the main ideas from the transcription process done earlier. The 7-column matrix had columns for interview questions, subordinate keywords, subordinate main points from conversation, elaboration examples from verbal to support the subordinate, occurrence of main idea transferred as key word, frequency of occurrences and lastly, ordering of discourse units. The last phase of data analysis was generation of themes. This was done by creating a three column matrix that reflected the Interview questions to the corresponding informants and their main ideas to create the themes.

\section{Findings}

This section of the paper presents the findings on student experiences with the user interface design and their learning process in the multimedia courseware as reflected the themes generated from the interview data to answer the research questions.

\section{How User Interface Design of Multimedia Courseware Enhances Learning Motivation}

The study found several themes that described the informants "perceptions with regard to learning motivation in the multimedia courseware. For example with regard to learning attention, three themes of attractive music, eye catching design and standard design emerged. 
The first and second themes are in line with Wang and Reeves (2007) who in their study on the effect of a web-based learning environment on student motivation in a science course. Using mixed method, the study found that half of the students interviewed revealed that video, animation and sound effects were major components that made students feel excited. While Faghih, Reza, and Katebi (2013) reports that background music makes learning easier, more successful and enjoyable For example Informant one and two stated that:

"..........the interface the graphic design was also kind of aaa you know the the kind of catchy elements........ because it's kind of interesting and then kind of looking very good" (Informant 1)

"It is stimulating and catchy..... Yes that music..... Very inviting......... very attractive...... Flashy" (Informant 2)

The third theme on standard design is in agreement with $\mathrm{Hu}$ (2008) whose study results suggest that a significant effect interface design on learner motivation, with learners who used the interface design with both usability improvement and motivational design showing the highest level of motivation. This was exemplified by informant one who noted that:

"........ The the standard design is very good" (Informant 1)

Three themes also recurred in line with how the interface fostered learning confidence and these were learner support, easy navigation, and clear instructions. In line with the first theme of learner support, Kanala, Nousiainen and Kankaanranta (2013)'s study on using a mobile application to support children's writing motivation, found that the use of a mobile application can have potential in supporting children's creative writing skills and their motivation to complete writing tasks. From the interviews, Informant 1, for example noted that:

"so the interface give you the $u$ know ok try again and then the person will all go again....... when you answer for the first time wrong...........then the interface will give you aaaa try again" (Informant 1)

The theme of ease of navigation is in line with Su and James (2006) whose results indicated that students in the content list group scored significantly higher than those in the embedded hyperlink group on the achievement posttest and had more positive attitudes toward the program. Navigation patterns indicated that students in the content list group and the map group visited more distinct pages than those in the embedded hyperlink group. In support, informants one and two said:

"Because the interface itself is have the button and you know.........There is clear navigation right" (Informant 1)

"The nature of the buttons. The buttons are in the right place........... The button is there the instruction is there" (Informant 2).

The theme on clear instructions is in line with Herrlinger (2011) who reports that providing additional embedded visual and verbal guidance for selecting, organizing and integrating relevant information supports learners in a more active way. This was supported by informant two when he pointed out that: 
"...the instruction is given adequately------On how to do it.... The

instruction that has been given is very clear and the button is very".

(Informant 2).

Satisfactory assessment and feedback emerged as the major themes regarding students' learning satisfaction. From the data, the informants said:

"Aa the question was motivating. the question was motivating. It was good......The assessment system is ok and motivating” (Informant 1).

"The feedback very ok........If you are good will praise you if you fail...... What I can say is that it is encouraging" (Informant 2).

\section{How User Interface Design of Multimedia Courseware Fosters Learning Interactivity}

Learner-content interaction, relation to personal experiences, reflective thinking emerged as the three themes on how the courseware interface design enhanced students' learning interactivity. This was evident when the informants noted that:

"Yes aaaa it stimulates my mind....To make it curious whether that happen to be true and having to relate to my experience...... You know triggered learning”. (Informant 2).

"Those registered words....For me to understand some of I just think think about them". (Informant 1).

The themes agree with Croxton (2014) found that interactivity is an important component of satisfaction and persistence for online learners, and that preferences for types of online interactivity vary according to type of learner. Thus it can be concluded that learning in multimedia learning environments is most effective when characterized by active engagement, frequent interaction and connections to real world contexts.

\section{How User Interface Design of Multimedia Courseware Manages Cognitive Load}

With regard to cognitive load while learning with multimedia courseware, students were asked how the interface design minimised their extraneous cognitive load, managed their intrinsic cognitive load and enhanced their germane load during the learning process. In terms of reducing their extraneous cognitive load, the themes of content organisation, content relevance, supportive learning, learner control, and visual design emerged. The first, second and fourth themes agree with Sii and Soon (2010) who found that additional redundant information that are relevant to the contents within and across the visual and aural channels give better motivation for organizing and structuring information for better learning. Findings of this study also suggest that cognitive load in multimedia-based learning can be minimized if adequate time is provided for comprehension and the pace of learning is under learner control. For example informant two said:

"Ok the content....Yes its relevant...... As many times as possible because you know it belongs to you you are using it by yourself......You have the control’.'(Informant 2). 
The theme of learning support is in agreement with Schrader and Bastiaens (2012) who found that games equipped with support devices enhances learning outcomes. Informant one gave an example:

"so the interface give you the you know ok try again and then the person will all go again. oohh that is correct.This is kind of aaaa motivation that that person will keep on trying trying". (Informant 1).

On the theme of visual design, Harper, Michailidou and Stevens (2009) reported that visual complexity with elements like text and how it is displayed, the colors used, and other stylistic and navigational features, such as graphics, tables, and hyperlinks may cause cognitive load. Yet De Koning, Tabbers, Rikers and Paas (2009) have also found that color coding can interfere with cognitive processing since the learner may associate certain concepts with specific colors. Moreover, when the same colors are repeated for another concept, can cause extraneous cognitive load. But in this study, informant two particularly noted that:

"The colors are okay” (Informant 1)

Regarding user interface and the intrinsic cognitive load, four themes were generated and these were relation to previous knowledge, Knowledge relevance, organised learning content and case-based learning. The two informants for example commented that:

"I think we are trying to relate it to our real life then we will create conscious". (Informant 1).

"when when we are stuck you know when we too relate it to that kind of scenario. So it will you know trigger your you know motivation". (Informant $1)$.

"Yes precisely what I was able to connect was during the spreadsheet that I was taught”. (Informant 2).

Four themes emerged in trying to answer the interview question on enhancing germane cognitive load and these were; sequences learning activities, learning review, linked content, focused learning and motivated learning. The four themes generally agree with with (Cheon and Grant (2016) who in their study on the effects of metaphorical interface on germane cognitive load in Web-based instruction found that a metaphorical interface enhanced learners' germane cognitive load and learning performance. In this study, the informants further elaborated thus:

"When things one at a time so student will focus on one at a time...... That one will enhance the concentration of that student and that student will fully understand that before moving to the next one" (Informant 2).

"It is aaa you know from from one one slide to another...Its kind of there is a linkage between aaa one another" (Informant 1). 


\section{User Interface Design Challenges in Using the Multimedia Courseware for Learning}

In trying to understand the challenges students faced while using the multimedia courseware, four themes emerged as hardware incompatibility, limited examples used, difficult content, and software incompatibility. The informants for example pointed out that:

"I don't have any challenges except the challenge of the doing using firefox". (Informant 2).

"Because my learning software is on old laptop so this one it it did not appear”.(Informant 1).

The themes of Limited examples use and difficult content was in line Lewis (2008) who found that learners who passively studied worked examples were significantly more efficient than those who actively solved problems. Informant 1 noted that:

"were significantly more efficient, than the practice learners..........The example is not too adequate.... In terms of the content I will say the content is for it might not be easy for the beginner". Informant 1).

\section{Suggestions for Improving User Interface Design of Multimedia Courseware}

Regarding their suggestions on how to improve the multimedia course interface design for better learning, the informants made several recommendations reflected in the themes like adding catchy features, consulting with users during design, use standard design approach, simplifying technical words, use adequate examples, design for compatibility, variation instructional techniques.

"Those technical terms need to be simplified.....I think rollover is better although it might be difficult or take time. To take time that rollover will serve as teacher's explanation quick referencel/. When the teacher is explaining in the class"'(Informant 2).

"So consulting all those you know group of people..... Will give you you know extra feedback to design better" (Informant 1).

"I see that if you want to use this type of module make it to be general.....For laymen to benefit all mostly for students some words those some words......Those technical terms need to be simplified" (Informant 2).

"Maybe we use the the animations....Animation is to to give extra features" (Informant 1).

The findings above agree with with Kamaruddin et al. (2009) who pointed out that interactive educational courseware is expected to fully support the teaching and learning activity and to create new ways of learning and teaching. Therefore, meaningful learning can be accomplished with the appropriate presentation of the interactive multimedia materials that enable learners to learn in more effective and efficient way and improve their learning outcome. 
Thus From the analysis of findings, the Multimedia courseware Interface usability model for enhanced learning is developed as depicted in Figure 2.

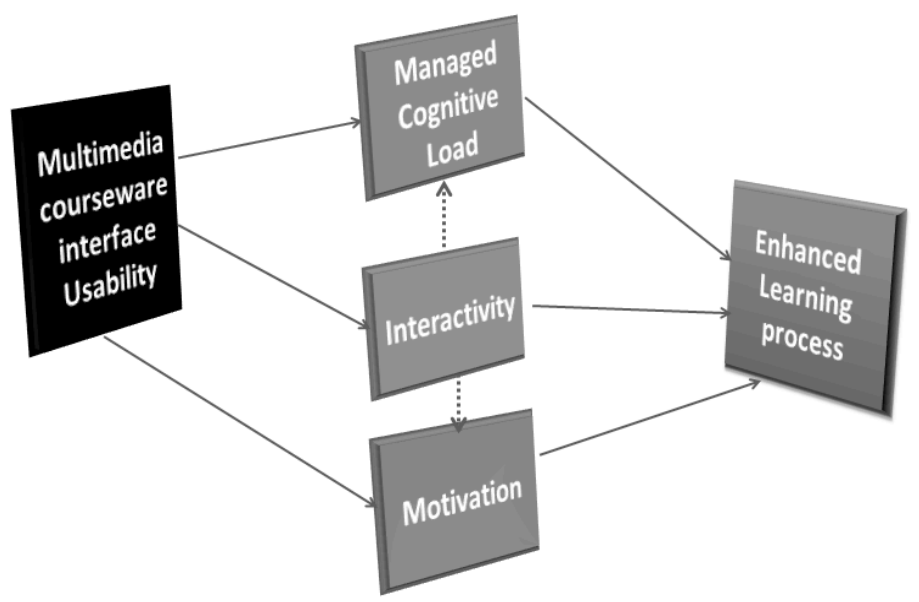

Figure 2: Interface Usability model for multimedia courseware

The model asserts that: Multimedia courseware Interface design usability (Navigation, Content and visual design) enhances Learning Motivation (Attention, Confidence and Satisfaction), manages cognitive load (Extraneous, Intrinsic and germane load), enhances interactivity (Cognitive and behavioral interactivity), hence enhanced learning process in Multimedia courseware. But, Enhanced interactivity (Cognitive and behavioral interactivity) also fosters Motivation and manages cognitive load, hence enhanced learning process in Multimedia courseware.

\section{Discussion and Conclusion}

Student learning today is increasingly being supported by an array of e-learning environments, the most common among these being multimedia courseware with diverse user interface designs. Since the key function of any interactive courseware is to motivate and help learners to learn meaningfully and assist them to be engaged more in their learning, it should be carefully designed and thoughtfully evaluated for meaningful learning to be accomplished. The interface design has significant impact on learning. For example E-learning interfaces that are user-friendly enhance learner engagement, ease information transfer and interaction between the learner and computer environment. Moreover, usable interfaces scaffold learner abilities of perception, organization, integration and recall of knowledge and focus on learning objectives. On the contrary, poorly designed courseware interface devoid of clear navigation and with ambiguity in instructions will distract student learning.

The findings of this study on how multimedia user interfaces foster student learning process are in tandem with Islam (2011) whose study found that users paid attention to issues of usability, functionality, navigation and interaction. Similarly, Li and Chen (2010) in a study on comparing Topic Browser interfaces with conventional tabbed browser interfaces found that TopicBrowser could reduce disorientation, enhance learners' retention, and increase the efficiency in completing a learning task. Our findings are further strengthened by Reis et al. (2012), whose study found that interfaces that hide advanced and extraneous features helps novice users to perform slightly better than novice users using a complete interface. 
This study's research findings will provide guideline to the design multimedia courseware interfaces so as to enhance student learning motivation, manage cognitive load and enhance interactivity. Given the fact this study is only a tip of the ice berg in the domain of user interface design for multimedia learning, it is thus recommended that further studies be carried on larger samples, using other research approaches and designs to enable for generalisability of the findings on user interface design and learning process in multimedia courseware. For example complex research designs involving rigorous experiments or with advanced statistical techniques like Structural Equation Modeling to unearth the intricate relationships between multimedia interface construct and student learning processes.

\section{References}

Ahmad, A., Ahmad, W., \& Wan, J. (2015). Multimedia Design Principles in Developing Virtual Reality Learning Application to increase students knowledge in islami funeral rites. Proceedings of INTCESSI5 2. International Conference on Education and Social Sciences, (Feburary), 421-429.

Al-kabi, M., \& Sharadgah, F. (2015). Studying the Impact of Using Multimedia Interactive Programs on Children's Ability to Learn Basic Math Skills, 10(3), 305-319.

Baker, S. E., \& Edwards, R. (2012). How many qualitative interviews is enough ? National Centre for Research Methods Review Paper. http://doi.org/10.1177/1525822X05279903

Bakri, A. (2014). A Conceptual Framework for Arabic Language Courseware Using Persuasive Design, 2, 1-6.

Centers for Disease Control and Prevention. (2013). CDC's E-learning Essentials: A guide for creating quality electronic learning. Antlanta.

Chandrasekera, T., \& Yoon, S.-Y. (2015). The Effect of Tangible User Interfaces on Cognitive Load in the Creative Design Process. In Proceedings of the 2015 IEEE International Symposium on Mixed and Augmented Reality - Media, Art, Social Science, Humanities and Design (pp. 6-8).

Cheon, J., \& Grant, M. M. (2016). The effects of metaphorical interface on germane cognitive load in Web-based instruction. Educational Technology Research and Development, 60(3), 399-420.

Chun-Yi, Shen and Hao-Ping, C. (2014). The relationship between interface design of Digital Game-based learning systems and flow experience and cognitive load of learners with different levels of prior knowledge. In Cross-Cultural Design (pp. 574584). Springer International Publishing.

Croxton, R. a. (2014). The Role of Interactivity in Student Satisfaction and Persistence in Online Learning. MERLOT Journal of Online Learning and Teaching, 10(2), 314325.

Currie, Q. T. (2008). Animation as Reality. Factors Impacting Cognitive Load in StudioBased E-learning. Capella University. 
De Koning, B. B., Tabbers, H. K., Rikers, R. M. J. P., \& Paas, F. (2009). Towards a Framework for Attention Cueing in Instructional Animations: Guidelines for Research and Design. Educational Psychology Review, 21(2), 113-140.

Debiase, M. (2009). Effects of color and animation on visual short -term memory in computer-environment learning tasks. Dissertation. West Virginia University.

Dorian, P. (2014). Interface Design for Learning for Learning: Design strategies for learning experiences. USA: New Riders.

Estapa, A., \& Nadolny, L. (2015). The Effect of an Augmented Reality Enhanced Mathematics Lesson on Student Achievement and Motivation. Journal of STEM Education, 16(3), 40-49.

Evans, C., \& Sabry, K. (2003). Evaluation of the Interactivity of Web-Based Learning Systems: Principles and Process. Innovations in Education and Teaching International, 40(1), 89-99.

Faghih, B.; Reza, M.A.; and Katebi, S. . (2013). User Interface Design for E-Learning Software. The International Journal of Soft Computing and Software Engineering, 3(3), 786-794.

Galitz, W. O. (2007). The Essential Guide to An Introduction to GUI Design Principles and Techniques.

Harper, S., Michailidou, E., \& Stevens, R. (2009). Toward a definition of visual complexity as an implicit measure of cognitive load. ACM Transactions on Applied Perception, 6(2), 1-18.

Herrlinger, S. (2011). Multimedia Learning in Primary schools: Multimedia Effects, Modality Effects and Attentional Guidance. Dissertation. Universitat Duisburg-Essen.

Hong, Z. W., Huang, Y. M., Hsu, M., \& Shen, W. W. (2016). Authoring Robot-Assisted Instructional Materials for Improving Learning Performance and Motivation in EFL Classrooms. Educational Technology, 19, 337-349.

Hsiung, L. Y., \& Lai, M. H. (2013). Improving learning results and reducing cognitive load through 3D courseware on color management and inspection instruction. Turkish Online Journal of Educational Technology, 12(3), 91-106.

Hsu, J. M., Chang, T. W., \& Yu, P. T. (2012). Learning effectiveness and cognitive loads in instructional materials of programming language on single and dual screens. Turkish Online Journal of Educational Technology, 11(2), 156-166.

Hu, Y. (2008). Motivation, usability and their interrelationships in a self-paced online learning environment. Virginia Polytechnic Institute and State University.

Ibrahim, M. A., Yusuf, A. M., Zohdi, M., Amin, M., \& Basir, N. (2016). Interactive Courseware : Quranic Verses on the Integration of Naqli and Aqli Knowledge, 4(1).

Islam, N. (2011). The Determinants of the Post-Adoption Satisfaction of Educators with an E-Learning System. Journal of Information Systems Education, 22(4), 319-331.

Kamaruddin, N; Park, J \& Hyun, N. (2009). Challenges of Malaysian developers in 
creating good interfaces for interactive courseware development in Malaysian educational context. Design Principles and Practices, 3(2).

Kanala, S., Nousiainen, T., \& Kankaanranta, M. (2013). Using a mobile application to support children's writing motivation. Interactive Technology and Smart Education, 10(1), 4-14. http://doi.org/10.1108/17415651311326419

Khan, B. . (2012). User Interface design for virtual environments:challenges and advances. Hershey: McWeadon Education.

Lai, Y. S., Tsai, H. H., \& Yu, P. T. (2011). Integrating annotations into a dual-slide PowerPoint presentation for classroom learning. Educational Technology and Society, 14(2), 43-57.

Lee, S., Noh, H., Lee, J., Lee, K., Lee, G. G., Sagong, S., \& Kim, M. (2011). On the effectiveness of Robot-Assisted Language Learning. European Association for Computer Assisted Language Learning, 23(1), 25-58.

Lewis, D. (2008). The Acquisition of Prodedural Skills: An Analysis of the workedExample Effect Using Demonstrations. University of South Florida.

Li, L. Y., \& Chen, G. D. (2010). A web browser interface to manage the searching and organizing of information on the web by learners. Educational Technology and Society, 13(4), 86-97.

Mukundan, J., \& Nimehchisalem, V. (2011). An Evaluation of English Language Teaching Courseware in Malaysia. English Language Teaching, 4(3), 142-150. http://doi.org/10.5539/elt.v4n3p142

Neo, M., Neo, K. T.-K., \& Tan, H. Y.-J. (2012). Applying Authentic Learning Strategies in a Multimedia ad Web Learning Environment (MWLE): Malaysia Students' Perspective. The Turkish Online Journal of Educational Technology, 11(3), 50-60.

O'Brien, H. L. (2010). The influence of hedonic and utilitarian motivations on user engagement: The case of online shopping experiences. Interacting with Computers, 22(5), 344-352.

Omale, N. M. (2010). Exploring the use of 3D multi user virtual environments for online problem-based learning. Northern Illinois University.

Rau, P. L. P. (2014). Cross-Cultural Design - , Held as Part of HCI International 2014, Proceedings. In 6th International Conference, CCD 2014. Greece.

Reis, H. M., Borges, S. S., Durelli, V. H. S., Fernando De S. Moro, L., Brandão, A. A. F., Barbosa, E. F., ... Bittencourt, I. I. (2012). Towards reducing cognitive load and enhancing usability through a reduced graphical user interface for a dynamic geometry system: An experimental study. Proceedings - 2012 IEEE International Symposium on Multimedia, ISM 2012.

Richardson, R. T., Drexler, T. L., \& Delparte, D. M. (2014). Color and Contrast in ELearning Design: A Review of the Literature and Recommendations for Instructional Designers and Web Developers. Journal of Online Learning \& Teaching, 10(4), 657670. 
Schrader, C., \& Bastiaens, T. (2012). Learning in Educational Computer Games for Novices: The Impact of Support Provision Types on Virtual Presence , Cognitive Load, and Learning Outcomes. International Review of Research in Open and Distance Learning, 13(3), 1-11.

Sii, Ching Hii; Soon, F. F. (2010). Effects of Multimedia Redundancy in History Learning among “Deep and Surface” Students. Asian Social Science, 6(6), 119-127.

Stefan, Livia and Moldoveanu, F. (2015). Gamified 3D virtual learning environment for improved students' motivation and learning evaluation. A case study on "3DUPB" campus (pp. 94-101). Bucharest.

Su, Y.; and James, D. (2006). Effect of Navigation Tools and Computer Confidence on Performance and Attitude in a Hypermedia Learning Environment. Journal of Educational Multimedia and Hypermedia, 15(1), 87-106.

Tsang, E. Y. M. (2010). Learner-Content Interactions And Learning Effectiveness: A Study Of Student Perceptions.

Wan Isa, W. M., Ahmad, F., Amin, M. A. M., Deris, M. S. M., Rozaimee, A., Wan Idris, W. M. R., \& Safei, S. D. (2010). Development and innovation of multimedia courseware for teaching and learning of KAFA subjects. ICCTD 2010 - 2010 2nd International Conference on Computer Technology and Development, Proceedings, (Icctd), 100-104.

Wang, S., \& Reeves, T. C. (2007). The effects of a web-based learning environment on student motivation in a high school earth science course. Educational Technology, Research and Development, 169-192.

Wang, W. F., Chen, C. M., \& Wu, C. H. (2015). Effects of Different Video Lecture Types on Sustained Attention, Emotion, Cognitive Load, and Learning Performance. Proceedings - 2015 IIAI 4th International Congress on Advanced Applied Informatics, IIAI-AAI 2015, (0), 385-390.

Yerasimou, T. (2010). Examining interactivity and flow in a blended course to advance blended learning practices. Dissertation. Indiana University. 